\title{
Antibody persistence and evidence of immune memory at 5 years following administration of the 9-valent HPV vaccine
}

\author{
Ana Guevara ${ }^{a}$, Robinson Cabello ${ }^{b}$, Linn Woelber ${ }^{c}$, Edson Duarte Moreira Jr ${ }^{d}$, Elmar Joura ${ }^{e}$, Olaf Reich ${ }^{f}$, \\ Christine Shields $^{\mathrm{g}}$, Misoo C. Ellison ${ }^{\mathrm{g}}$, Amita Joshi ${ }^{\mathrm{g}}$, Alain Luxembourg ${ }^{\mathrm{g}, *}$ \\ ${ }^{a}$ Research Unit, Pablo Tobon Uribe Hospital, Medellin, Antioquia, Colombia \\ b Vía Libre CRS, Jr. Paraguay 490, Lima 01, Peru \\ ${ }^{\mathrm{C}}$ University Medical Center Hamburg-Eppendorf, Hamburg, Germany \\ ${ }^{\mathrm{d}}$ Associação Obras Sociais Irmã Dulce and Oswaldo Cruz Foundation, Brazilian Ministry of Health, Bahia, Brazil \\ ${ }^{\mathrm{e}}$ Medical University of Vienna, Comprehensive Cancer Center, Vienna, Austria \\ ${ }^{\mathrm{f}}$ Department of Obstetrics \& Gynecology, Medical University of Graz, Austria \\ ${ }^{\mathrm{g}}$ Merck \& Co., Inc., Kenilworth, NJ, USA
}

\section{A R T I C L E I N F O}

\section{Article history:}

Received 28 March 2017

Received in revised form 3 July 2017

Accepted 5 July 2017

Available online 5 August 2017

\section{Keywords:}

Human papillomavirus

9vHPV vaccine

Immunogenicity

Clinical trial

Immune memory

\begin{abstract}
A B S T R A C T
Background: The 9-valent HPV (9vHPV) vaccine was developed to prevent infection and disease related to 9 HPV types (HPV6/11/16/18/31/33/45/52/58) which cause approximately 90\% of cervical cancers, HPVrelated vulvar, vaginal and anal cancers, and genital warts worldwide. In a pivotal efficacy study, the $9 \mathrm{vHPV}$ vaccine prevented infection and disease due to the 9 vaccine types. Duration of protection remains to be determined. Vaccines that induce long-term protection are generally characterized by the generation of immune memory. The purpose of this report is to assess the persistence of HPV antibody response and existence of immune memory at 5 years post-vaccination.

Methods: A subset of subjects $(\mathrm{N}=150)$ who received 3 doses of $9 \mathrm{vHPV}$ vaccine at day 1 , month 2 and month 6 in the pivotal efficacy study continued in a study extension and received a fourth dose of 9 vHPV vaccine at month 60. Serum HPV antibody levels were measured pre-dose 4 and at 7 and 28 days post-dose 4 by competitive Luminex immunoassay. Adverse events were assessed using a vaccination report card.

Results: HPV antibodies induced following the 3-dose series of 9vHPV vaccine in the base study persisted through month 60 with seropositivity rates ranging from $77.5 \%$ to $100 \%$. Geometric mean titers at 1 week and 1 month post-dose 4 were $1.25-4.10$ and 1.65-4.88-fold higher, respectively, than levels observed 1 month following the completion of the three-dose primary series. Seropositivity rates were $>99 \%$ and $100 \%$ at 1 week and 1 month post-dose 4 , respectively. The fourth dose of 9vHPV vaccine was generally well tolerated.

Conclusions: A three-dose regimen of the 9vHPV vaccine induced persistent HPV antibody response through 5 years post-vaccination. Administration of a fourth dose resulted in a strong anamnestic response to all 9 vaccine types. These findings suggest that the efficacy of the 9vHPV vaccine will be long lasting.
\end{abstract}

Conclusions: Clinical Trials.gov Identifier: NCT00543543.

(c) 2017 Elsevier Ltd. All rights reserved.

\section{Introduction}

Human Papillomavirus (HPV) is responsible for $5 \%$ of the global cancer burden with including nearly all cervical cancers and a substantial proportion of vulvar, vaginal, anal, penile and

\footnotetext{
* Corresponding author at: Merck \& Co., Inc., 351N. Sumneytown Pike, North Wales, PA 19454, USA

E-mail address: alain_luxembourg@merck.com (A. Luxembourg).
}

oropharyngeal cancers representing $>600,000$ new cases annually worldwide [1]. HPV infection is also associated with acquisition of anogenital warts [1]. Prophylactic vaccination thus offers the potential to prevent HPV-related cancers and other diseases. A 9valent HPV (types 6/11/16/18/31/33/45/52/58) (9vHPV) vaccine (Gardasil 9, Merck \& Co., Inc., Kenilworth, NJ) was developed to provide protection against the HPV types already covered by the quadrivalent HPV (types 6/11/16/18) (qHPV) vaccine and HPV types $31 / 33 / 45 / 52 / 58$, which are, after HPV types $16 / 18$, the most 
frequent HPV types associated with cervical cancer worldwide [2]. Based on epidemiological studies, the 9vHPV vaccine could potentially prevent approximately $90 \%$ of cervical cancers and HPVrelated vulvar and vaginal cancers, and $70-85 \%$ high-grade cervical disease (precancers) in females, and 90\% of HPV-related anal cancers and genital warts in both genders worldwide [3-6]. The 9vHPV vaccine was licensed in the United States in 2014, in Canada, the European Union and Australia in 2015, and in other countries in 2015 and 2016.

In a pivotal efficacy trial conducted in young women 1626 years old, the $9 \mathrm{vHPV}$ vaccine prevented $\sim 97 \%$ high-grade cervical, vulvar and vaginal disease associated with HPV $31 / 33 / 45 / 52 / 58$ and was generally well tolerated [7]. This study also demonstrated that the 9vHPV vaccine elicited robust anti HPV 6/11/16/18 antibody responses that were non-inferior to the antibody responses generated by the qHPV vaccine. The efficacy of the 9vHPV vaccine against infection and disease caused by HPV 6/11/16/18 was inferred based on these immunogenicity results [7]. The duration of protection afforded by the $9 \mathrm{vHPV}$ vaccine is unknown. Protection induced by prophylactic HPV vaccines is thought to be antibody-mediated [8]. Long-lived protective antibody responses are especially relevant as the risk of infection may last throughout the sexual life of an individual. Guidelines set forth by the World Health Organization (WHO) for the development of prophylactic HPV vaccines require assessing memory immune responses [9]. As per WHO guidance "Induction of immune memory should be assessed by means of evaluating immune responses to additional doses of vaccine administered at planned intervals following completion of the primary series". Thus an extension of the pivotal efficacy study of the 9vHPV vaccine was conducted to assess the persistence of vaccine type antibody responses at 5 years post-vaccination. Additionally, we evaluated whether reexposure to the antigen via a challenge dose of the vaccine would lead to the development of an anamnestic response.

\section{Methods}

\subsection{Study design}

This study (Merck Protocol V503-001-04; NCT00543543) is an open-label extension of the pivotal efficacy study of the 9vHPV vaccine (Merck Protocol V503-001; NCT00543543). The base study was a dose-ranging, safety, efficacy and immunogenicity study of the $9 \mathrm{vHPV}$ vaccine in young women 16-26 years of age at enrollment [7]. The extension study was initiated after investigators, site personnel and study subjects were unblinded to vaccination groups. The extension study enrolled subjects in 2 cohorts: Cohort 1 in a sub study to assess immune memory in subjects who received a 3-dose series of 9vHPV vaccine in the base study; Cohort 2 in a sub study to offer 9vHPV vaccine to subjects in the control arm (qHPV vaccine) of the base study. The rest of this report is focused on results from Cohort 1 . The overall study design of the extension study and the results from Cohort 2 are summarized in the supplement for completeness of information. Subjects in Cohort $1(\mathrm{~N}=150)$ were randomly selected from 4 sites in Europe (2 each in Austria and Germany) and 3 sites in Latin America (1 each in Brazil, Colombia, and Peru). The study was conducted in accordance with the principles of Good Clinical Practice and was approved by the regulatory agencies from all participating countries and by the institutional review boards with jurisdiction over the clinical sites. Informed consent was obtained after the nature and possible consequences of the studies had been fully explained. The study extension was initiated on 21-Jul-2014. The last participant visit for Cohort 1 occurred on 14-Jan-2015.

\subsection{Study population}

Subjects from Europe and Latin America were enrolled in Cohort 1 based on maximum participation from these geographical areas in the base study [7]. Subjects from Denmark, Norway and Sweden were not considered for this extension study as these subjects are being evaluated for long-term effectiveness in another study extension (Merck Protocol V503-021; NCT02653118) [10]. Site selection was based on the principal investigators' interest in conducting the trial, site evaluation and number of subjects enrolled at the site in the base study. Subjects eligible to participate were (1) enrolled in part B of the base study and randomized to the 9vHPV vaccine group and (2) included in per-protocol immunogenicity analyses in the base study [7]. Subjects who participated in the study were randomly selected within the study sites from the pool of eligible subjects.

\subsection{Vaccine administration and serum collection}

In the base study, subjects received 3 doses of 9vHPV vaccine on day 1 , month 2 and month 6 . Serum samples were collected on day 1 and months $3,7,12,24,36$ and 42 . In the study extension, a challenge dose of the 9vHPV vaccine (dose 4) was administered at month 60. Serum samples were collected at months 60 (prevaccination dose 4), month $60+1$ week and month 61. Subjects completed the study extension at month 61 .

\subsection{Immunogenicity assessment}

Serum samples were assessed for HPV $6 / 11 / 16 / 18 / 31 / 33 / 45 / 52 / 58$ antibodies by a multiplexed competitive Luminex Immunoassay (cLIA; HPV-9 cLIA Version 2.0; performed by PPD Vaccines and Biologics Lab, Wayne, PA, USA) [11] In the HPV-9 cLIA assay, antibody titers for each individual HPV type are determined through competition with type-specific monoclonal antibodies; thus, it is not possible to directly compare assay results across HPV types.

\subsection{Safety assessment}

Subjects were observed for 30 min after vaccination dose 4 for any immediate reaction. They received a vaccination report card (VRC) to record their oral temperature for 5 days, and injectionsite and systemic adverse events (AEs) for total of 15 days, starting from the day of vaccination. The VRC prompted the recording of oral temperature and injection-site AEs of pain, swelling and erythema for 5 days including the day of vaccination. Serious AEs (predefined as those events that resulted in death, were deemed life-threatening, led to a persistent or significant disability, required hospitalization, or were associated with a congenital anomaly, cancer or other important medical event) were collected for the entire duration of the study extension irrespective of causality. Participants rated each AE as mild (awareness of symptom but easily tolerated), moderate (discomfort enough to cause interference with usual activity), or severe (incapacitating with inability to work or do usual activity); injection-site AEs of swelling and erythema were rated by size. Investigators were asked to assign causality to AEs on the basis of exposure, time course, likely cause, and consistency with the vaccine's known profile [12].

\subsection{Data analysis}

Immunogenicity analysis was conducted in the per-protocol immunogenicity (PPI) population. To be included in the PPI population, subjects had to: receive 3 doses of 9vHPV vaccine in the base study and provide month 7 serology results within 
pre-specified day ranges; be seronegative at day 1 and PCRnegative from day 1 through month 7 to the HPV type being analyzed; have no other protocol deviations that could interfere with the evaluation of subject's immune response to the study vaccine as judged by the study director. To be included in the PPI analysis for HPV 6 and 11, subjects had to be negative at the aforementioned time points for both HPV 6 and 11. To be included in the PPI analysis for any other vaccine HPV type, subjects needed to only be negative for the HPV type under evaluation. Further, the month $60+1$ week and month 61 results had to be obtained within pre-specified day ranges relative to month 60 to be included in the PPI immunogenicity analyses.

The following immunogenicity summary endpoints were analyzed: (1) Geometric mean titers (GMTs) and seropositivity rates for each of the 9 vaccine HPV types at month 60, month 60 +1 week and month 61 ; (2) the fold-changes in GMTs at month $60+1$ week and month 61 relative to month 7 ; and (3) the percentages of subjects who have a 5 -foldrise, 10 -foldrise, and 20 foldrise (foldrise refers to geometric mean foldrise [GMFR]) at month $60+1$ week and month 61 relative to month 60 .

The analysis for GMT and GMFR are typically based on the natural $\log$ transformed antibody titers or log foldrises. The means and confidence intervals are constructed based on the assumption that $\log$ titers or log foldrises follow a t-distribution. Then the mean and confidence interval are back transformed to get the corresponding estimate and 95\% confidence intervals. Confidence intervals for the percentages of subjects who have a 5-foldrise, 10-foldrise, and 20foldrise are computed by the exact method without adjusting for multiplicity. For seropositivity rates, a subject with a cLIA titer at or above the predetermined serostatus cutoff for a given HPV type is considered seropositive for that type. The serostatus cutoffs for HPV types $6,11,16,18,31,33,45,52$ and 58 are 30, 16, 20, 24, $10,8,8,8$ and $8 \mathrm{mMU} / \mathrm{mL}$, respectively.

All subjects who received a fourth dose of 9vHPV vaccine and had follow-up data were included in the analysis of safety data.

\section{Results}

\subsection{Subject disposition}

Subjects $(N=150)$ were enrolled from Austria $(n=22)$, Brazil $(n=21)$, Colombia $(n=49)$, Germany $(n=33)$, and Peru $(n=25)$. Baseline characteristics of subjects enrolled in extension study are shown in Table 1. Age distribution of subjects in the extension study was similar to that in the base study [7]. All 150 subjects received three doses of $9 \mathrm{vHPV}$ vaccine in the base study, a fourth dose in the study extension and completed the study extension. The average time interval between dose 3 and dose 4 was 58.53 months. A summary of subjects that were excluded from the PPI analyses is provided in the supplementary materials (Table S1). The primary reason for exclusion was HPV seropositivity at day 1 . Nine subjects either had their Month $60+1$ week visit or Month 61 visit out of acceptable days range; immunogenicity results at the corresponding visits were excluded from PPI analyses.

\subsection{Immunogenicity}

In a longitudinal analysis of HPV GMTs, including the base study and study extension, GMTs peaked after the administration of the third dose of vaccine, decreased from month 7 to month 36 , and reached a plateau afterward (Fig. 1). At month 60 (approximately 5 years post-dose 3 ), most subjects (77.5-100\%) remained seropositive to the 9 vaccine types (Table 2). Administration of a fourth dose of the $9 \mathrm{vHPV}$ vaccine at month 60 resulted in a rapid rise in
Table 1

Subject characteristics.

\begin{tabular}{|c|c|c|}
\hline & \multicolumn{2}{|c|}{$\begin{array}{l}\text { 9vHPV vaccine } \\
(N=150)\end{array}$} \\
\hline & $\mathrm{n}$ & $(\%)$ \\
\hline Subjects in population & 150 & 100 \\
\hline \multicolumn{3}{|c|}{ Age at enrollment in the base study (Years) } \\
\hline - Mean (SD) & $22.1(2.4)$ & \\
\hline - Median & 22.0 & \\
\hline - Range & 17 to 26 & \\
\hline \multicolumn{3}{|l|}{ Race } \\
\hline - Black or African American & 12 & 8.0 \\
\hline - Multi-Racial & 82 & 54.7 \\
\hline - White & 56 & 37.3 \\
\hline \multicolumn{3}{|l|}{ Region } \\
\hline - Europe & 55 & 36.7 \\
\hline - Latin America & 95 & 63.3 \\
\hline \multicolumn{3}{|c|}{ Interval between Dose 3 and Dose 4 (Months) } \\
\hline - Average (SD) & $58.63(3.36)$ & \\
\hline - Median & 58.12 & \\
\hline - Range & $51.6-66.8$ & \\
\hline
\end{tabular}

$\mathrm{N}=$ Number of subjects enrolled to the cohort 1 vaccination group who received the 4 th dose injection.

Interval between Dose 1 and Dose 4: average: 64.53 months (SD: 3.31); median: 64.05 months (range: 57.9-72.5).

HPV GMTs for all 9 vaccine types (Fig. 1). The GMTs were higher at month $60+1$ week and month 61 ( 1 week and 1 month postdose 4 , respectively) than at month 7 ( 1 month post-dose 3 ) for all 9 types (Table 2). Over 99\% and 100\% of the subjects became seropositive at 1 week and 1 month post-dose 4 , respectively.

Anti-HPV GMTs, 1 week post-dose 4 were 1.25 - to 4.10 -fold higher than GMTs obtained 1 month following the completion of the three-dose primary series, i.e., at month 7 . At 1 month postdose 4 , fold changes in vaccine-specific anti-HPV GMTs relative to month 7 ranged from 1.65 to 4.88 . A summary of GMFRs and the percentages of subjects with a $\geq 5$-fold, $\geq 10$-fold and $\geq 20$ fold rises in vaccine type anti-HPV antibody levels is provided in Table 3: $76.5-93.0 \%$ and $87.8-97.1 \%$ of subjects had $\geq 5$-fold rises in GMTs at 1 week post-dose 4 and 1 month post-dose 4 , respectively.

\subsection{Safety}

Table 4 summarizes adverse events and elevated temperatures reported after each dose of vaccination in the subjects enrolled in the extension study. There were no serious vaccine-related adverse events reported after any vaccination in the base study or the present extension study. No cases of death or discontinuation due to an adverse event were reported. A higher percentage of subjects reported injection-site AEs after dose 4 (84.0\%) than after doses 1,2 , or $3(70.7 \%, 69.3 \%, 67.3 \%$, respectively). The most common $(\geq 5 \%)$ injection-site AEs were pain, swelling and erythema; most (88-100\%) were mild-to-moderate in intensity. The most common $(\geq 5 \%)$ vaccine-related systemic AE after dose 4 was headache (6.7\%). The proportion of subjects with a fever $\left(\geq 37.8^{\circ} \mathrm{C}\right)$ was similar after dose $1,2,3$, or $4(2.7 \%, 2.0 \%, 2.7 \%, 3.3 \%$, respectively); fevers following vaccination were mostly low-grade $\left(<38.9^{\circ} \mathrm{C}\right)$. One serious $\mathrm{AE}$ was reported in the study extension: a subject experienced post-procedural wound infection 6 days after undergoing salpingectomy; this event occurred at 47 days post-dose 4 , resolved after 18 days, and was not considered related to vaccination. No subject discontinued from the study extension due to an AE. One subject became pregnant during the study extension and delivered a healthy baby. 


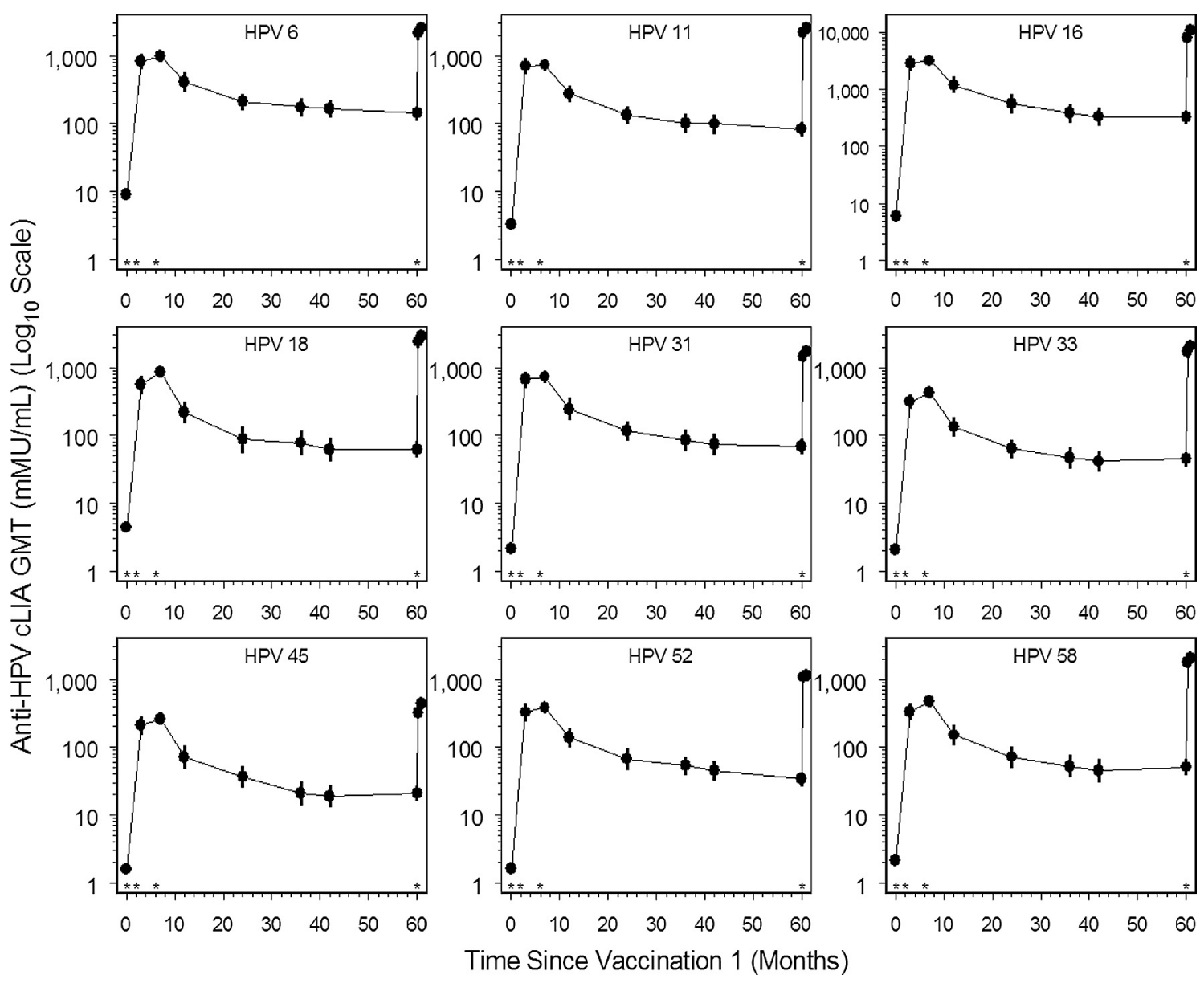

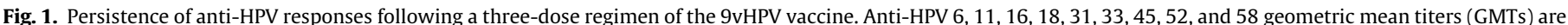

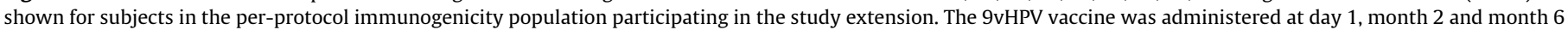
in the base study and at month 60 in the study extension as denoted by asterisks along the X axis of the graphs. Error bars represent $95 \%$ confidence intervals.

\section{Discussion}

These results show that administration of a 3-dose regimen of $9 v H P V$ vaccine to young women $16-26$ years of age induces antibody responses against all 9vHPV vaccine types that persist for at least 5 years post-vaccination. GMTs peaked one month after dose 3 , then declined steadily, reaching a plateau approximately 2 years thereafter, and remaining stable through approximately 5 years of follow-up. Most subjects remained seropositive at that time, with seropositivity rates ranging from $77.5 \%$ to $100 \%$ depending on the HPV type. A hallmark of vaccines that induce long-term protection is the generation of immune memory, characterized by an amplified antibody response (anamnestic response) to a challenge dose of antigen, with decreased lag time to response, and increased sensitivity to antigen [13]. In this study, administration of a challenge dose of the 9vHPV vaccine resulted in a potent anamnestic response, thus indicating the existence of immune memory 5 years after the completion of a 3-dose series of 9vHPV vaccine. These results suggest that a single booster dose may be sufficient to restore HPV antibody levels consistent with protective efficacy, should vaccine efficacy wane over time. Administration of the fourth dose of 9vHPV vaccine was generally well tolerated; a potentially useful information if a booster dose of vaccine is needed in the future.

Similar results were obtained in a previous study with the qHPV vaccine which demonstrated that anti HPV 6/11/16/18 antibodies persisted through 5-years post-vaccination and vigorous antibody responses were detected upon administration of a challenge dose, consistent with an anamnestic response [14]. Thus, studies with the 9vHPV and qHPV vaccines have provided functional evidence for generation of immune memory following vaccination, which reinforces the similarity of the immunogenicity profiles of the two vaccines observed in the base study [7].

Seropositivity rates at month 60 were lower for HPV 18 and 45 (77.5\% and $81.1 \%$, respectively) than for the other HPV vaccine types. This is reminiscent of earlier observations of lower seropositivity rate for HPV 18 (64.7\%) compared to the other HPV vaccine types at 5 years post-vaccination with qHPV vaccine [14]. Since the minimum antibody level required for protection against HPV disease or infection is unknown, the lack of measurable antibody cannot be interpreted as absence of protection. Animal studies suggest that very low HPV antibody levels (e.g., 100fold lower than the threshold of detection of existing immunoassays) may still be protective [8]. In qHPV vaccine studies, there was no evidence of HPV vaccine type-related breakthrough disease associated with waning antibody levels [15]; lack of detection of HPV 18 antibodies reflected the sensitivity of the assay rather than absence of antibody [16]. Efficacy of the 9vHPV vaccine was comparable with qHPV vaccine for HPV 18 and remained high for HPV 45 for the entire duration of the efficacy follow-up [7,17]. The robust anamnestic response to all vaccine HPV types shown in this report indicates the persistence of the immune response.

The small sample size and limited duration of follow up may be considered a limitation of the study. However, the results of a similar study with the qHPV vaccine [14]were followed subsequently 
Table 2

Summary of anti-HPV geometric mean titers (GMT) and seropositivity rates for 9vHPV vaccine types $6,11,16,18,31,33,45,52$, and 58 .

\begin{tabular}{|c|c|c|c|c|}
\hline Assay and time point & $\mathrm{n}$ & GMT (mMU/ml) (95\% C.I.) & Fold change in GMT from month 7 & Seropositivity (\%) (95\%C.I.) \\
\hline \multicolumn{5}{|l|}{ Anti HPV 6} \\
\hline Month 7 & 112 & $\begin{array}{l}989.9 \\
(869.2,1,127.2)\end{array}$ & NA & $\begin{array}{l}100 \\
(96.8,100)\end{array}$ \\
\hline Month 60 (pre-fourth dose) & 101 & $\begin{array}{l}143.1 \\
(117.9,173.7)\end{array}$ & NA & $\begin{array}{l}95.0 \\
(88.8,98.4)\end{array}$ \\
\hline Month $60+1$ week & 109 & $\begin{array}{l}2,180.5 \\
(1,826.2,2,603.7)\end{array}$ & $\begin{array}{l}2.22 \\
(1.79,2.75)\end{array}$ & $\begin{array}{l}100 \\
(96.7,100)\end{array}$ \\
\hline Month 61 & 109 & $\begin{array}{l}2,585.0 \\
(2,239.5,2,983.8)\end{array}$ & $\begin{array}{l}2.57 \\
(2.20,3.00)\end{array}$ & $\begin{array}{l}100 \\
(96.7,100)\end{array}$ \\
\hline \multicolumn{5}{|l|}{ Anti HPV 11} \\
\hline Month 7 & 112 & $\begin{array}{l}729.3 \\
(631.6,842.1)\end{array}$ & NA & $\begin{array}{l}100 \\
(96.8,100)\end{array}$ \\
\hline Month 60 (pre-fourth dose) & 112 & $\begin{array}{l}82.9 \\
(68.1,100.9)\end{array}$ & NA & $\begin{array}{l}95.5 \\
(89.9,98.5)\end{array}$ \\
\hline Month $60+1$ week & 109 & $\begin{array}{l}2,228.7 \\
(1,852.5,2,681.3)\end{array}$ & $\begin{array}{l}3.09 \\
(2.47,3.87)\end{array}$ & $\begin{array}{l}100 \\
(96.7,100)\end{array}$ \\
\hline Month 61 & 109 & $\begin{array}{l}2,548.7 \\
(2,191.4,2,964.3)\end{array}$ & $\begin{array}{l}3.43 \\
(2.89,4.07)\end{array}$ & $\begin{array}{l}100 \\
(96.7,100)\end{array}$ \\
\hline \multicolumn{5}{|l|}{ Anti HPV 16} \\
\hline Month 7 & 128 & $\begin{array}{l}3,142.1 \\
(2,787.0,3,542.4)\end{array}$ & NA & $\begin{array}{l}100 \\
(97.2,100)\end{array}$ \\
\hline Month 60 (pre-fourth dose) & 128 & $\begin{array}{l}324.4 \\
(266.7,394.7)\end{array}$ & NA & $\begin{array}{l}100 \\
(97.2,100)\end{array}$ \\
\hline Month $60+1$ week & 126 & $\begin{array}{l}7,986.3 \\
(6,795.7,9,385.6)\end{array}$ & $\begin{array}{l}2.54 \\
(2.11,3.07)\end{array}$ & $\begin{array}{l}100 \\
(97.1,100)\end{array}$ \\
\hline Month 61 & 123 & $\begin{array}{l}10,904.3 \\
(9,605.6,12,378.7)\end{array}$ & $\begin{array}{l}3.38 \\
(2.91,3.92)\end{array}$ & $\begin{array}{l}100 \\
(97.0,100)\end{array}$ \\
\hline \multicolumn{5}{|l|}{ Anti HPV 18} \\
\hline Month 7 & 142 & $\begin{array}{l}852.5 \\
(746.8,973.0)\end{array}$ & NA & $\begin{array}{l}100 \\
(97.4,100)\end{array}$ \\
\hline Month 60 (pre-fourth dose) & 142 & $\begin{array}{l}62.5 \\
(49.5,78.9)\end{array}$ & NA & $\begin{array}{l}77.5 \\
(69.7,84.0)\end{array}$ \\
\hline Month $60+1$ week & 138 & $\begin{array}{l}2,399.0 \\
(2,049.4,2,808.1)\end{array}$ & $\begin{array}{l}2.81 \\
(2.34,3.38)\end{array}$ & $\begin{array}{l}100 \\
(97.4,100)\end{array}$ \\
\hline Month 61 & 137 & $\begin{array}{l}2,907.9 \\
(2,531.1,3,340.7)\end{array}$ & $\begin{array}{l}3.34 \\
(2.90,3.84)\end{array}$ & $\begin{array}{l}100 \\
(97.3,100)\end{array}$ \\
\hline \multicolumn{5}{|l|}{ Anti HPV 31} \\
\hline Month 7 & 135 & $\begin{array}{l}732.3 \\
(635.9,843.2)\end{array}$ & NA & $\begin{array}{l}100 \\
(97.3,100)\end{array}$ \\
\hline Month 60 (pre-fourth dose) & 135 & $\begin{array}{l}69.2 \\
(56.6,84.4)\end{array}$ & NA & $\begin{array}{l}96.3 \\
(91.6,98.8)\end{array}$ \\
\hline Month $60+1$ week & 131 & $\begin{array}{l}1,462.2 \\
(1,263.9,1,691.5)\end{array}$ & $\begin{array}{l}2.01 \\
(1.68,2.40)\end{array}$ & $\begin{array}{l}100 \\
(97.2,100)\end{array}$ \\
\hline Month 61 & 130 & $\begin{array}{l}1,745.4 \\
(1,538.8,1,979.8)\end{array}$ & $\begin{array}{l}2.31 \\
(2.01,2.66)\end{array}$ & $\begin{array}{l}100 \\
(97.2,100)\end{array}$ \\
\hline \multicolumn{5}{|l|}{ Anti HPV 33} \\
\hline Month 7 & 141 & $\begin{array}{l}418.2 \\
(368.9,473.9)\end{array}$ & NA & $\begin{array}{l}100 \\
(97.4,100)\end{array}$ \\
\hline Month 60 (pre-fourth dose) & 141 & $\begin{array}{l}44.7 \\
(37.0,54.1)\end{array}$ & NA & $\begin{array}{l}96.5 \\
(91.9,98.8)\end{array}$ \\
\hline Month $60+1$ week & 137 & $\begin{array}{l}1,709.0 \\
(1,466.7,1,991.2)\end{array}$ & $\begin{array}{l}4.10 \\
(3.40,4.93)\end{array}$ & $\begin{array}{l}100 \\
(97.3,100)\end{array}$ \\
\hline Month 61 & 136 & $\begin{array}{l}2,094.9 \\
(1,848.7,2,373.9)\end{array}$ & $\begin{array}{l}4.88 \\
(4.24,5.63)\end{array}$ & $\begin{array}{l}100 \\
(97.3,100)\end{array}$ \\
\hline \multicolumn{5}{|l|}{ Anti HPV 45} \\
\hline Month 7 & 148 & $\begin{array}{l}262.1 \\
(224.6,305.8)\end{array}$ & NA & $\begin{array}{l}100 \\
(97.5,100)\end{array}$ \\
\hline Month 60 (pre-fourth dose) & 148 & $\begin{array}{l}20.8 \\
(17.0,25.5)\end{array}$ & NA & $\begin{array}{l}81.1 \\
(73.8,87.0)\end{array}$ \\
\hline Month $60+1$ week & 144 & $\begin{array}{l}323.0 \\
(277.2,376.5)\end{array}$ & $\begin{array}{l}1.25 \\
(1.05,1.49)\end{array}$ & $\begin{array}{l}99.3 \\
(96.2,100)\end{array}$ \\
\hline Month 61 & 143 & $\begin{array}{l}440.0 \\
(386.9,500.4)\end{array}$ & $\begin{array}{l}1.65 \\
(1.45,1.87)\end{array}$ & $\begin{array}{l}100 \\
(97.5,100)\end{array}$ \\
\hline \multicolumn{5}{|l|}{ Anti HPV 52} \\
\hline Month 7 & 134 & $\begin{array}{l}383.1 \\
(332.2,441.7)\end{array}$ & NA & $\begin{array}{l}100 \\
(97.3,100)\end{array}$ \\
\hline Month 60 (pre-fourth dose) & 134 & $\begin{array}{l}33.7 \\
(27.6,41.1)\end{array}$ & NA & $\begin{array}{l}91.0 \\
(84.9,95.3)\end{array}$ \\
\hline Month $60+1$ week & 131 & $\begin{array}{l}1,078.1 \\
(907.2,1,281.2)\end{array}$ & $\begin{array}{l}2.82 \\
(2.25,3.54)\end{array}$ & $\begin{array}{l}100 \\
(97.2,100)\end{array}$ \\
\hline
\end{tabular}


Table 2 (continued)

\begin{tabular}{|c|c|c|c|c|}
\hline Assay and time point & $\mathrm{n}$ & GMT (mMU/ml) (95\% C.I.) & Fold change in GMT from month 7 & Seropositivity (\%) (95\%C.I.) \\
\hline Month 61 & 129 & $\begin{array}{l}1,131.5 \\
(991.6,1,291.1)\end{array}$ & $\begin{array}{l}2.85 \\
(2.41,3.38)\end{array}$ & $\begin{array}{l}100 \\
(97.2,100)\end{array}$ \\
\hline \multicolumn{5}{|l|}{ Anti HPV 58} \\
\hline Month 7 & 132 & $\begin{array}{l}476.1 \\
(414.4,547.0)\end{array}$ & NA & $\begin{array}{l}100 \\
(97.2,100)\end{array}$ \\
\hline Month 60 (pre-fourth dose) & 132 & $\begin{array}{l}50.9 \\
(40.9,63.3)\end{array}$ & NA & $\begin{array}{l}92.4 \\
(86.5,96.3)\end{array}$ \\
\hline Month $60+1$ week & 129 & $\begin{array}{l}1,801.8 \\
(1,530.5,2,121.2)\end{array}$ & $\begin{array}{l}3.84 \\
(3.15,4.69)\end{array}$ & $\begin{array}{l}100 \\
(97.2,100)\end{array}$ \\
\hline Month 61 & 127 & $\begin{array}{l}2,024.6 \\
(1,803.1,2,273.2)\end{array}$ & $\begin{array}{l}4.16 \\
(3.60,4.81)\end{array}$ & $\begin{array}{l}100 \\
(97.1,100)\end{array}$ \\
\hline
\end{tabular}

$\mathrm{n}=$ number of subjects contributing to the analysis.

Table 3

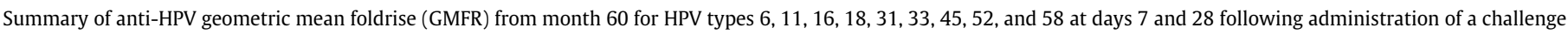
(fourth) dose of 9vHPV vaccine.

\begin{tabular}{|c|c|c|c|c|c|c|}
\hline & \multicolumn{3}{|c|}{1 week post-fourth dose } & \multicolumn{3}{|c|}{4 weeks post-fourth dose } \\
\hline & $\mathrm{n}$ & $\mathrm{m}$ & Estimate (95\% CI) & $\mathrm{n}$ & $\mathrm{m}$ & Estimate (95\% CI) \\
\hline Anti-HPV 6 GMFR & 98 & NA & $14.55(11.14,19.01)$ & 98 & NA & $16.85(13.52,20.99)$ \\
\hline$\geq$ 5-foldrise & 98 & 75 & $76.5 \%(66.9 \%, 84.5 \%)$ & 98 & 86 & $87.8 \%(79.6 \%, 93.5 \%)$ \\
\hline$\geq 10$-foldrise & 98 & 60 & $61.2 \%(50.8 \%, 70.9 \%)$ & 98 & 65 & $66.3 \%(56.1 \%, 75.6 \%)$ \\
\hline$\geq 20$-foldrise & 98 & 40 & $40.8 \%(31.0 \%, 51.2 \%)$ & 98 & 47 & $48.0 \%(37.8 \%, 58.3 \%)$ \\
\hline Anti-HPV 11 GMFR & 109 & NA & $27.36(20.84,35.93)$ & 109 & NA & $29.84(23.41,38.03)$ \\
\hline$\geq 5$-foldrise & 109 & 95 & $87.2 \%(79.4 \%, 92.8 \%)$ & 109 & 103 & $94.5 \%(88.4 \%, 98.0 \%)$ \\
\hline$\geq 10$-foldrise & 109 & 82 & $75.2 \%(66.0 \%, 83.0 \%)$ & 109 & 93 & $85.3 \%(77.3 \%, 91.4 \%)$ \\
\hline$\geq 20$-foldrise & 109 & 65 & $59.6 \%(49.8 \%, 68.9 \%)$ & 109 & 68 & $62.4 \%(52.6 \%, 71.5 \%)$ \\
\hline Anti-HPV 16 GMFR & 126 & NA & $24.80(19.39,31.72)$ & 123 & NA & $32.02(25.56,40.11)$ \\
\hline$\geq 5$-foldrise & 126 & 109 & $86.5 \%(79.3 \%, 91.9 \%)$ & 123 & 117 & $95.1 \%(89.7 \%, 98.2 \%)$ \\
\hline$\geq 10$-foldrise & 126 & 90 & $71.4 \%(62.7 \%, 79.1 \%)$ & 123 & 100 & $81.3 \%(73.3 \%, 87.8 \%)$ \\
\hline$\geq 20$-foldrise & 126 & 74 & $58.7 \%(49.6 \%, 67.4 \%)$ & 123 & 82 & $66.7 \%(57.6 \%, 74.9 \%)$ \\
\hline Anti-HPV 18 GMFR & 138 & NA & $38.80(29.94,50.27)$ & 137 & NA & $46.24(37.03,57.74)$ \\
\hline$\geq 5$-foldrise & 138 & 125 & $90.6 \%(84.4 \%, 94.9 \%)$ & 137 & 130 & $94.9 \%(89.8 \%, 97.9 \%)$ \\
\hline$\geq 10$-foldrise & 138 & 115 & $83.3 \%(76.0 \%, 89.1 \%)$ & 137 & 121 & $88.3 \%(81.7 \%, 93.2 \%)$ \\
\hline$\geq 20$-foldrise & 138 & 90 & $65.2 \%(56.6 \%, 73.1 \%)$ & 137 & 108 & $78.8 \%(71.0 \%, 85.3 \%)$ \\
\hline Anti-HPV 31 GMFR & 131 & NA & $21.38(17.16,26.63)$ & 130 & NA & $24.26(20.05,29.36)$ \\
\hline$\geq 5$-foldrise & 131 & 113 & $86.3 \%(79.2 \%, 91.6 \%)$ & 130 & 120 & $92.3 \%(86.3 \%, 96.2 \%)$ \\
\hline$\geq 10$-foldrise & 131 & 99 & $75.6 \%(67.3 \%, 82.7 \%)$ & 130 & 109 & $83.8 \%(76.4 \%, 89.7 \%)$ \\
\hline$\geq 20$-foldrise & 131 & 71 & $54.2 \%(45.3 \%, 62.9 \%)$ & 130 & 76 & $58.5 \%(49.5 \%, 67.0 \%)$ \\
\hline Anti-HPV 33 GMFR & 137 & NA & $37.90(29.92,48.01)$ & 136 & NA & $45.75(37.30,56.12)$ \\
\hline$\geq 5$-foldrise & 137 & 125 & $91.2 \%(85.2 \%, 95.4 \%)$ & 136 & 132 & $97.1 \%(92.6 \%, 99.2 \%)$ \\
\hline$\geq 10$-foldrise & 137 & 116 & $84.7 \%(77.5 \%, 90.3 \%)$ & 136 & 123 & $90.4 \%(84.2 \%, 94.8 \%)$ \\
\hline$\geq 20$-foldrise & 137 & 97 & $70.8 \%(62.4 \%, 78.3 \%)$ & 136 & 104 & $76.5 \%(68.4 \%, 83.3 \%)$ \\
\hline Anti-HPV 45 GMFR & 144 & NA & $15.89(13.07,19.33)$ & 143 & NA & $20.47(17.15,24.43)$ \\
\hline$\geq 5$-foldrise & 144 & 125 & $86.8 \%(80.2 \%, 91.9 \%)$ & 143 & 131 & $91.6 \%(85.8 \%, 95.6 \%)$ \\
\hline$\geq 10$-foldrise & 144 & 97 & $67.4 \%(59.1 \%, 74.9 \%)$ & 143 & 107 & $74.8 \%(66.9 \%, 81.7 \%)$ \\
\hline$\geq 20$-foldrise & 144 & 54 & $37.5 \%(29.6 \%, 45.9 \%)$ & 143 & 73 & $51.0 \%(42.6 \%, 59.5 \%)$ \\
\hline Anti-HPV 52 GMFR & 131 & NA & $31.99(24.31,42.12)$ & 129 & NA & $31.33(24.98,39.30)$ \\
\hline$\geq 5$-foldrise & 131 & 117 & $89.3 \%(82.7 \%, 94.0 \%)$ & 129 & 119 & $92.2 \%(86.2 \%, 96.2 \%)$ \\
\hline$\geq 10$-foldrise & 131 & 100 & $76.3 \%(68.1 \%, 83.3 \%)$ & 129 & 111 & $86.0 \%(78.8 \%, 91.5 \%)$ \\
\hline$\geq 20$-foldrise & 131 & 79 & $60.3 \%(51.4 \%, 68.7 \%)$ & 129 & 85 & $65.9 \%(57.0 \%, 74.0 \%)$ \\
\hline Anti-HPV 58 GMFR & 129 & NA & $36.18(27.94,46.84)$ & 127 & NA & $38.84(31.01,48.66)$ \\
\hline$\geq 5$-foldrise & 129 & 120 & $93.0 \%(87.2 \%, 96.8 \%)$ & 127 & 121 & $95.3 \%(90.0 \%, 98.2 \%)$ \\
\hline$\geq 10$-foldrise & 129 & 107 & $82.9 \%(75.3 \%, 89.0 \%)$ & 127 & 109 & $85.8 \%(78.5 \%, 91.4 \%)$ \\
\hline$\geq 20$-foldrise & 129 & 80 & $62.0 \%(53.1 \%, 70.4 \%)$ & 127 & 88 & $69.3 \%(60.5 \%, 77.2 \%)$ \\
\hline
\end{tabular}

GMFR $=$ Geometric mean fold rise.

$\mathrm{n}=$ number of subjects in the analysis population with valid pre- and post-dose 4 serology data.

$\mathrm{m}=$ number of subjects with the specific fold rise from pre-dose 4 to post-dose 4 .

by the demonstration of long-term immunity and effectiveness through 10 years post-dose 3 [18]. Results with the qHPV vaccine are relevant to the 9vHPV vaccine since the two vaccines share HPV 6/11/16/18 antigens and are produced using the same manufacturing process. The use of intramuscular vaccination to mimic antigenic exposure (in place of a natural exposure) can be consid- ered as an additional constraint of the study as natural infection may presumably occur via mucosal route. However, exposing participants to live viruses would not be ethical and mucosal exposure to HPV pseudovirions would only model viral entry but not the subsequent steps of viral infection. Immune memory is mediated by the generation and persistence of long-lived memory B cells 
Table 4

Adverse events reported from day 1 to day 15 following a vaccination visit in subjects who received 9vHPV vaccine.

\begin{tabular}{|c|c|c|c|c|c|c|c|c|}
\hline & \multicolumn{8}{|c|}{ 9vHPV Vaccine } \\
\hline & \multicolumn{2}{|c|}{$\begin{array}{l}\text { After dose } 1 \\
(\mathrm{~N}=150)\end{array}$} & \multicolumn{2}{|c|}{$\begin{array}{l}\text { After dose } 2 \\
(\mathrm{~N}=150)\end{array}$} & \multicolumn{2}{|c|}{$\begin{array}{l}\text { After dose } 3 \\
(\mathrm{~N}=150)\end{array}$} & \multicolumn{2}{|c|}{$\begin{array}{l}\text { After dose } 4 \\
(\mathrm{~N}=150)\end{array}$} \\
\hline & Count & $(\%)$ & Count & $(\%)$ & Count & $(\%)$ & Count & $(\%)$ \\
\hline With one or more AEs ${ }^{\dagger}$ & 121 & $(80.7)$ & 114 & $(76.0)$ & 108 & $(72.0)$ & 131 & $(87.3)$ \\
\hline Injection-site event ${ }^{\ddagger}$ & 106 & (70.7) & 104 & $(69.3)$ & 101 & $(67.3)$ & 126 & $(84.0)$ \\
\hline Pain & 104 & $(69.3)$ & 103 & $(68.7)$ & 98 & $(65.3)$ & 124 & $(82.7)$ \\
\hline Mild & 94 & $(62.7)$ & 85 & $(56.7)$ & 66 & $(44.0)$ & 79 & $(52.7)$ \\
\hline Moderate & 10 & $(6.7)$ & 15 & $(10.0)$ & 29 & (19.3) & 42 & $(28.0)$ \\
\hline Severe & 0 & $(0.0)$ & 3 & $(2.0)$ & 3 & $(2.0)$ & 3 & $(2.0)$ \\
\hline Swelling & 12 & $(8.0)$ & 28 & $(18.7)$ & 33 & $(22.0)$ & 49 & $(32.7)$ \\
\hline Mild $(0$ to $\leq 2.5 \mathrm{~cm})$ & 9 & $(6.0)$ & 21 & $(14.0)$ & 24 & $(16.0)$ & 32 & $(21.3)$ \\
\hline Moderate $(>2.5 \mathrm{~cm}$ to $\leq 5.0 \mathrm{~cm})$ & 1 & $(0.7)$ & 4 & $(2.7)$ & 5 & $(3.3)$ & 12 & $(8.0)$ \\
\hline Severe $(>5.0 \mathrm{~cm})$ & 0 & $(0.0)$ & 3 & $(2.0)$ & 4 & $(2.7)$ & 5 & $(3.3)$ \\
\hline Erythema & 10 & $(6.7)$ & 18 & $(12.0)$ & 19 & $(12.7)$ & 33 & $(22.0)$ \\
\hline Mild $(0$ to $\leq 2.5 \mathrm{~cm})$ & 9 & $(6.0)$ & 16 & $(10.7)$ & 18 & $(12.0)$ & 26 & $(17.3)$ \\
\hline Moderate $(>2.5 \mathrm{~cm}$ to $\leq 5.0 \mathrm{~cm})$ & 1 & $(0.7)$ & 1 & $(0.7)$ & 1 & $(0.7)$ & 7 & $(4.7)$ \\
\hline Severe $(>5 \mathrm{~cm})$ & 0 & $(0.0)$ & 1 & $(0.7)$ & 0 & $(0.0)$ & 0 & $(0.0)$ \\
\hline Systemic event $^{\dagger}$ & 79 & $(52.7)$ & 53 & (35.3) & 43 & $(28.7)$ & 57 & $(38.0)$ \\
\hline Vaccine-related $^{\S}$ systemic event & 12 & $(8.0)$ & 5 & $(3.3)$ & 5 & $(3.3)$ & 23 & $(15.3)$ \\
\hline Headache & 3 & $(2.0)$ & 1 & $(0.7)$ & 1 & $(0.7)$ & 10 & $(6.7)$ \\
\hline Serious event ${ }^{\dagger}$ & 0 & $(0.0)$ & 0 & $(0.0)$ & 0 & $(0.0)$ & 0 & $(0.0)$ \\
\hline Vaccine-related $^{\S}$ event & 0 & $(0.0)$ & 0 & $(0.0)$ & 0 & $(0.0)$ & 0 & $(0.0)$ \\
\hline Death & 0 & $(0.0)$ & 0 & $(0.0)$ & 0 & $(0.0)$ & 0 & $(0.0)$ \\
\hline Discontinuation because of an $\mathrm{AE}^{\dagger}$ & 0 & $(0.0)$ & 0 & $(0.0)$ & 0 & $(0.0)$ & 0 & $(0.0)$ \\
\hline \multicolumn{9}{|c|}{ With the following maximum temperatures } \\
\hline$\geq 37.8{ }^{\circ} \mathrm{C}$ & 4 & $(2.7)$ & 3 & $(2.0)$ & 4 & $(2.7)$ & 5 & $(3.3)$ \\
\hline$\geq 38.9^{\circ} \mathrm{C}$ & 1 & $(0.7)$ & 0 & $(0.0)$ & 0 & $(0.0)$ & 0 & $(0.0)$ \\
\hline
\end{tabular}

Injection-site and systemic AEs shown are those with incidence $\geq 5 \%$ at any of the vaccination visits.

$\mathrm{N}=$ Number of subjects as-treated who received at least 1 dose of the indicated vaccine and had at least one follow-up visit for adverse event.

All subjects $(\mathrm{N}=150)$ provided oral temperature data for each vaccination visit.

$\dagger$ Days 1-15 following vaccination visit.

* Days 1-5 following vaccination visit.

$\S$ As determined by the reporting investigator.

- Study vaccination withdrawn.

and requires many precise interactions between the innate and adaptive immune systems. Although the anamnestic immune response observed in our study suggests the presence of circulating memory lymphocytes, the actual lymphocytes were not directly studied. Nonetheless, existence of memory B cells in subjects immunized with the qHPV vaccine was demonstrated by Scherer et al. [19] who isolated HPV-specific memory B cells from qHPV vaccine recipients; antibodies cloned from these cells potently neutralized HPV pseudovirions and the cells exhibited immunological signatures of long-lived memory B cells. In another report, the same group showed that administration of a single dose of qHPV vaccine in HPV 16-seropositive women elicited a robust anamnestic HPV 16 antibody response together with HPV 16-specific memory B cells that expressed type specific neutralizing antibodies [20]. The qHPV vaccine is known to protect seropositive women against subsequent disease due to the corresponding vaccine HPV type [21]. Given that 9vHPV and qHPV vaccines use the same manufacturing process and have similar immunogenicity profiles, one can assume that these results are applicable to the 9vHPV vaccine.

To date, these results are the longest follow-up of antibody persistence post-administration of the 9vHPV vaccine. Understanding the durability of immunogenicity, protection and safety of the $9 \mathrm{vHPV}$ vaccine is essential towards development of vaccines that provide long term protective efficacy. A study to evaluate longterm immunogenicity and effectiveness of the 9vHPV vaccine is underway [10]. Results of a study to compare the immunogenicity of 2-dose regimens in girls and boys 9-14 years of age compared with a 3-dose regimen in young women 16-26 years of age have been reported [22]. Additional follow-up to assess antibody persistence and immune memory following administration of 2 doses of $9 v H P V$ vaccine is ongoing.

\section{Conclusion}

The demonstration of sustained efficacy up to 67 months postdose 3 (median 43 months) [23], persistence of HPV antibody response, and evidence of immune memory at 5 years post-dose 3 , suggest that a 3 -dose regimen of $9 \mathrm{vHPV}$ vaccine will induce long-term protection.

5.1. Investigators for Cohort 1 of Protocol V503-001-04: Austria: Elmar Joura, Olaf Reich; Brazil: Edson Moreira; Colombia: Ana Guevara; Germany: Klaus Greven, Linn Woelber; Peru: Robinson Cabello.

\section{Funding source}

This study was funded by Merck \& Co., Inc., Kenilworth, NJ, USA.

\section{Financial disclosures}

Other than employees of Merck \& Co., Inc., Kenilworth, NJ, USA, all authors have been investigators for the sponsor. Employees may hold stock and/or stock options in the company.

\section{Conflicts of interest}

Ana Guevara, Robinson Cabello, Linn Woelber, Edson Duarte Moreira Jr., Elmar Joura, Olaf Reich were investigators supported by research grants from Merck Sharp and Dohme, a subsidiary of Merck \& Co., Inc., Kenilworth, NJ, USA. 
Christine Shields, Misoo C. Ellison, Amita Joshi and Alain Luxembourg are employees of Merck \&Co., Inc., Kenilworth, NJ, USA and may hold stock options.

\section{Author contributions}

All co-authors meet all four of the criteria described in the 'Publication Ethics: Authorship' section of the Author Guidelines.

Alain Luxembourg and Amita Joshi: drafted the initial manuscript.

Ana Guevara, Robinson Cabello, Linn Woelber, Edson Duarte Moreira Jr., Elmar Joura, Olaf Reich: participant enrollment, data collection/acquisition.

Misoo C. Ellison and Alain Luxembourg: study concept/design, statistical analysis.

All Authors: data analysis/interpretation, reviewed, and revised the manuscript, and approved the final manuscript.

\section{Acknowledgments}

The authors would like to thank all the study participants and the study-site personnel who contributed to the study, as well as Ms. Karyn Davis, Merck \& Co., Inc., Kenilworth, NJ, USA for editorial assistance.

\section{Appendix A. Supplementary material}

Supplementary data associated with this article can be found, in the online version, at http://dx.doi.org/10.1016/j.vaccine.2017.07. 017.

\section{References}

[1] Forman D, De Martel C, Lacey CJ, Soerjomataram I, Lortet-Tieulent J, Bruni L, et al. Global burden of human papillomavirus and related diseases. Vaccine 2012;30(suppl 5):F12-23.

[2] De Sanjose S, Quint WG, Alemany L, Geraets DT, Klaustermeier JE, Lloveras B, et al. Human papillomavirus genotype attribution in invasive cervical cancer: a retrospective cross-sectional worldwide study. Lancet Oncol 2010;11:1048-56.

[3] Serrano B, De Sanjose S, Tous S, Quiros B, Munoz N, Bosch X, et al. Human papillomavirus genotype attribution for HPVs 6, 11, 16, 18, 31, 33, 45, 52 and 58 in female anogenital lesions. Eur J Cancer 2015;51:1732-41.

[4] Joura EA, Ault KA, Bosch FX, Brown D, Cuzick J, Ferris D, et al. Attribution of 12 high-risk human papillomavirus genotypes to infection and cervical disease. Cancer Epidemiol Biomarkers Prev 2014;23:1997-2008.

[5] Alemany L, Saunier M, Alvarado-Cabrero I, Quiros B, Salmeron J, Shin HR, et al Human papillomavirus DNA prevalence and type distribution in ana carcinomas worldwide. Int. J. Cancer 2014;136:98-107.
[6] Garland SM, Steben M, Sings HL, James M, Lu S, Railkar R, et al. Natural history of genital warts: analysis of the placebo arm of 2 randomized phase III trials of a quadrivalent human papillomavirus (types $6,11,16$, and 18) vaccine. J Infect Dis 2009;199:805-14.

[7] Joura EA, Giuliano AR, Iversen OE, Bouchard C, Mao C, Mehlsen J, et al, A 9valent HPV vaccine against infection and intraepithelial neoplasia in women. $\mathrm{N}$ Engl J Med 2015;372:711-23.

[8] Stanley M, Pinto LA, Trimble C. Human papillomavirus vaccines-immune responses. Vaccine 2012;30(suppl 5):F83-7.

[9] WHO. Guidelines to assure quality, safety, and efficacy of recombinant HPV virus-like particle vaccines; 2006 <http://screening.iarc.fr/doc/WHO_vaccine_ guidelines_2006.pdf>.

[10] Luxembourg A, Kjaer SK, Nygard M, Ellison MC, Group T, Marshall JB, et al. Design of a long-term follow-up effectiveness, immunogenicity and safety study of women who received the 9-valent human papillomavirus vaccine. Contemp Clin Trials 2017:52:54-61.

[11] Roberts C, Green T, Hess E, Matys K, Brown MJ, Haupt RM, et al. Development of a human papillomavirus competitive luminex immunoassay for 9 HPV types. Hum Vaccin Immunother 2014;10:2174-83.

[12] Moreira Jr ED, Block SL, Ferris D, Giuliano AR, Iversen OE, Joura EA, et al. Safety profile of the 9-valent HPV vaccine: a combined analysis of 7 phase III clinical trials. Pediatrics 2016;138.

[13] Zinkernagel RM. On differences between immunity and immunological memory. Curr Opin Immunol 2002;14:523-36.

[14] Olsson S-E, Villa LL, Costa R, Petta C, Andrade R, Malm C, et al. Induction of immune memory following administration of a prophylactic quadrivalent human papillomavirus (HPV) types 6/11/16/18 L1 virus-like-particle vaccine. Vaccine 2007;25:4931-9.

[15] Joura EA, Kjaer SK, Wheeler CM, Sigurdsson K, Iversen OE, Hernandez-Avila M, et al. HPV antibody levels and clinical efficacy following administration of a prophylactic quadrivalent HPV vaccine. Vaccine 2008;26:6844-51.

[16] Brown DR, Garland SM, Ferris DG, Joura E, Steben M, James M, et al. The humoral response to Gardasil over four years as defined by Total IgG and competitive Luminex immunoassay. Hum Vaccin 2011;7(2):230-8.

[17] GARDASIL EPAR Product Information <http://www.ema.europa.eu/docs/en GB/document_library/EPAR___Product_Information/human/003852/WC500189111. pdf> [accessed on 19 Feb 2017].

[18] Kjaer Sk NM, Dillner J, Munk C, Marshall B, Hansen B, et al. Long-term effectiveness and safety af Gardasil ${ }^{\mathrm{TM}}$ in the Nordic countries. European Research Organization on Genital Infection and Neoplasia 2015. 2015;OC: 6-1.

[19] Scherer EM, Smith RA, Simonich CA, Niyonzima N, Carter JJ, Galloway DA. Characteristics of memory B cells elicited by a highly efficacious HPV vaccine in subjects with no pre-existing immunity. PLoS Pathog 2014;10:e1004461.

[20] Scherer EM, Smith RA, Gallego DF, Carter JJ, Wipf GC, Hoyos M, et al. A single human papillomavirus vaccine dose improves B cell memory in previously infected subjects. EBioMedicine 2016;10:55-64.

[21] Olsson Se KS, Sigurdsson K, Iversen O, Hernandez-Avila M, Wheeler C, et al Evaluation of quadrivalent HPV 6/11/16/18 vaccine efficacy against cervical and anogenital disease in subjects with serological evidence of prior vaccine type HPV infection. Hum Vacc 2009;5:696-704.

[22] Iversen OE, Miranda MJ, Ulied A, et al. Immunogenicity of the 9-valent HPV vaccine using 2-dose regimens in girls and boys vs 3-dose regimen in women. JAMA 2016;316:2411-21.

[23] European Medicines Agency - Gardasil 9: EPAR- product information [available at: <http://wwwemaeuropaeu/ema/indexjsp?curl=pages/medicines/ human/medicines/003852/human_med_001863jsp\&mid=WC0b01ac058001d124> [accessed 23 February 2017]. 